\title{
Non-isolated multiple input multilevel output DC-DC converter for hybrid power system
}

Ameen M. Al-Modaffer, Amer A. Chlaihawi, Husam A. Wahhab

Department of Electrical Engineering, University of Kufa, Iraq

\begin{tabular}{l}
\hline \hline Article Info \\
\hline Article history: \\
Received Dec 1, 2019 \\
Revised Mar 3, 2020 \\
Accepted Mar 17, 2020 \\
\hline
\end{tabular}

Keywords:

Boost converter

Dc-dc converter

Multilevel output

Multiple input

Semiconductor current stress

Switching duty cycle

\begin{abstract}
The utilization of multisources of energy in a compact and an effective power system gains an essential role in power electronic industry. As such, the design and simulation of a new non-isolated Multiple Input Multilevel Output (MIMLO) DC-DC converter for hybrid power system is presented. The MIMLO DC-DC converter can be integrated in renewable energy, such as fuel cells, wind turbines and photovoltaic arrays etc, to get the best output voltages. The MIMLO DC-DC converter powers the load from renewable energy sources through the independence of the availability of other sources. The proposed topology has been simulated by using MATLAB/Simulink software to testify the performance control operation of the Multiple Input Multilevel Output DC-DC converter. The results of the carried-out simulation favor the usage of multi-input voltage, rather than a single input voltage. The MIMLO design has the advantages of a simple configuration, reduced number of switches, fewer components, high efficiency, and high conversion ratio. The Multilevel Output DC-DC converter provides high voltage transfer with low size inductors, reduction of losses, low stress voltage on switches and diodes.
\end{abstract}

Copyright $\odot 2020$ Institute of Advanced Engineering and Science. All rights reserved.

\section{Corresponding Author:}

Ameen M. Al-Modaffer,

Department of Electrical Engineering, University of Kufa, Najaf, Iraq.

Email: ameenm.hadi@uokufa.edu.iq

\section{INTRODUCTION}

The rapid growth of daily industrial applications and the enormous exploitation and utilization of fossil energy production have led to increased greenhouse gas emissions, environmental pollution, and other environmental damages [1-4]. Therefore, renewable sources of energy, such as photovoltaic energy, energy harvester, wind energy, fuel cell energy, etc, can be employed to simultaneously deliver continuous power to loads [5-8]. Renewable energy resources are becoming attractive to obtain efficient and clean energy sources. Although renewable energy resources have low output voltage, during the last few decades, the researchers and scientists have shown great deal of interest to utilize maximum energy from multiple renewable energy resources $[9,10]$. It is possible to select a feasible topology, depending upon the application by considering many features like cost, reliability, and flexibility. Multiple input DC-DC converter has the advantages of a high system efficiency, light weight, small size, and high power density [11-13]. These advantages have led to an increasing demand in many areas for multiple inputs, and high voltage gain DC-DC converters [14]. The demand for the DC-DC converters have increased rapidly and attractively in many power electronic application and renewable energy sources. Generally, the output voltage of the renewable energy sources have a low output generated voltage $[15,16]$. The general concept involves utilizing a multiple inputs DC-DC converter to generate a desired DC level by using a specific level of DC input voltage. DC-DC converters are basically made up of a power semiconductor switches, diodes, inductors, capacitors and DC power supplies [17]. The boost converter is a non-isolated DC-DC converter topology, which is commonly 
utilized for voltage step-up [18, 19]. For the high output voltage, the duty ratio should be around 1. In general, the duty ratio will be limited, because of the parasitic parameters of each component [20-22]. Threrefore, Multiple input DC-DC converters grabs the attention of researcher to carry out research on multiple input multilevel output DC-DC converters [23-27].

The proposed multiple input multilevel output DC-DC converters are widely used in the modern power electronics applications. Theoretical results of this study were compared with simulations to validate the proposed topology model. This paper is organized as follows: Section 2 is destined for the development of the topology introduction and modes of operation. Section 3 introduced simulation results, as well as discussions and the benefits of the proposed model. Finally, Section 4 includes conclusions and summarization.

\section{TOPOLOGIES AND MODES OF OPERATION}

The basic structure of the proposed multiple input multi level output DC-DC converter is introduced in Figure 1. The proposed topology is a hybrid separated into two parts. The first part is named DC input voltage level generation, which is responsible for level generating in a positive polarity. The advantage of the first part is to supply the demand with the desired output voltage levels through a range of input sources depending on utilization. Also, the energy input sources can power the load independently from the availability of the rest of input sources. The basic cell of the proposed multiple inputs structure consists of two switches and a DC source. The switches are separated from each other. A series switch is connected with a DC source, which is termed voltage adder. A parallel switch is connected with the same DC source, which is termed subtracter. Therefore, the related switches must be controlled in a way that prevents occurring short circuit. However, the proposed cell is symmetric, so, the number of cells should be connected in series for high voltage output.

The second part is named multilevel boost DC-DC converter. This part requires high frequency switches to generate the required DC output voltage. In this paper we will design, analyze, and discuss Three Inputs Multilevel Output (TIMLO) DC-DC converter as presented in Figure 2. A multi level output boost DC DC converter (MLOBC) is a DC-DC converter achieves a wider step-up voltage compare with the conventional boost DC-DC converter. A TIMLO DC-DC converter is composed of eight active semiconductor unidirectional switches $(S 1, S 2, S 3, S 4, S 5, S 6, S 7$ and $S 8)$, two diodes (D1 and D2), inductor $(L)$, two capacitors $(C 1$ and $C 2)$, and a load resistance $R$. The DC voltage input level for the first-generation part of TIMLO DC-DC converter can operate in seven different operation states as presented in Table 1.

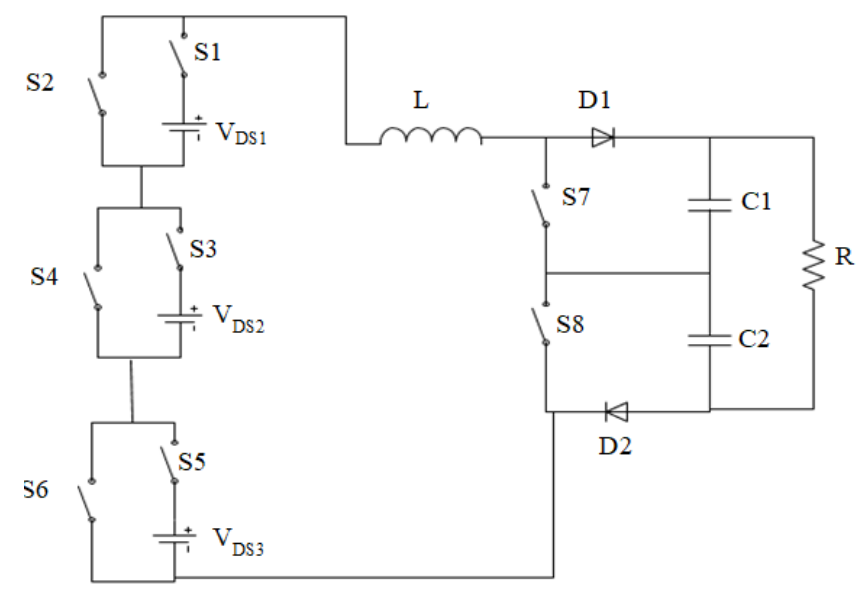

Figure 1. Proposed multiple input multi level output DC-DC converter

To simplify the analysis of the DC-DC converter circuit, ideal active semiconductor switches were used. The inductor is large enough to meet the high voltage requirement and low input current ripple. The capacitors $C 1$ and $C 2$ are equal in values. The resistor used in the circuit is assumed to be linear, time-invariant, and frequency independent. The operating principle of the MLOBC converter is similar to that of the conventional boost converter with a larger power capacity and the capacitors votage equal to half of the output voltage. The MLOBC has four operational modes, their sequence control relys on the voltage balance between the output capacitors [20]. 


\begin{tabular}{cccccccc}
\multicolumn{7}{c}{ Table 1. The various switches test } \\
\hline State & S1 & S2 & S3 & S4 & S5 & S6 & Vin \\
\hline 1 & 1 & 0 & 0 & 1 & 0 & 1 & $\mathrm{~V}_{\mathrm{DS} 1}$ \\
2 & 0 & 1 & 1 & 0 & 0 & 1 & $\mathrm{~V}_{\mathrm{DS} 2}$ \\
3 & 0 & 1 & 0 & 1 & 1 & 0 & $\mathrm{~V}_{\mathrm{DS} 3}$ \\
4 & 1 & 0 & 1 & 0 & 0 & 1 & $\mathrm{~V}_{\mathrm{DS} 1}+\mathrm{V}_{\mathrm{DS} 2}$ \\
5 & 1 & 0 & 0 & 1 & 1 & 0 & $\mathrm{~V}_{\mathrm{DS} 1}+\mathrm{V}_{\mathrm{DS} 3}$ \\
6 & 0 & 1 & 1 & 0 & 1 & 0 & $\mathrm{~V}_{\mathrm{DS} 2}+\mathrm{V}_{\mathrm{DS} 3}$ \\
7 & 1 & 0 & 1 & 0 & 1 & 0 & $\mathrm{~V}_{\mathrm{DS} 1}+\mathrm{V}_{\mathrm{DS} 2}+\mathrm{V}_{\mathrm{DS} 3}$ \\
\hline
\end{tabular}

\subsection{Operation modes}

By considering the proposed modulation strategy, there are four statuses for " $S 7 \& S 8$ " in their periodic switching, described as follows: $S 7 \& S 8=\{11,10,01$, and 00$\}$. Logic 1 represents the active switches $\mathrm{S} 7, \mathrm{~S} 8$ in their "ON" state, and logic 0 represents $\mathrm{S} 7, \mathrm{~S} 8$ in their "OFF" state.

Mode 1:

In this operation mode of MLOBC with in the time interval $0 \leq \mathrm{t} \leq \delta \mathrm{Ts}$, both switching transistors $\mathrm{S} 7$ and S8 are in conduction mode. Whereas both diodes D1 and D2, are reverse biased. The inductor current increases as the load current is supplied by $\mathrm{C} 1$ and $\mathrm{C} 2$. Figure 2(a) shows the equivalent circuit corresponding to this state. The inductor L is charged in parallel by the DC supply Vin. However, the inductor L will be storing energy from the DC supply.

Mode 2:

In this time interval, the switch $S 7$ is turned $O N$ whereas switch $S 8$ is turned $O F F$. The diode $D 1$ is in $O F F$ state, while $D 2$ is in $O N$ condition. In this mode of operation, the stored energy in the inductor L is delivered to the load, since diode $D 2$ is in the forward bias condition. The current flows from DC input source Vin to the load through inductors $L$, capacitor $C 2$, diode $D 2$, and the output capacitor $V_{C 2}=V_{O} / 2$. The current path during this period is depicted in Figure 2(b).

Mode 3:

The switch $S 7$ is turned $O F F$ and switch $S 8$ is turned $O N$. The diode $D 1$ is in $O N$ state, while $D 2$ is in $O F F$ condition. The voltage of the inductor has a negative value. The stored energy in $\mathrm{L}$ is pumped to $C l$ to charge while energy of $C 2$ discharges to the load. The equivalent circuit and current path during this period are depicted in Figure 2(c).

Mode 4:

In this mode, both switches, $S 7$ and $S 8$, are turned $O F F$. The diodes, $D 1$ and $D 2$, are turned $O N$ state. The voltage of inductor has a negative value and the energy is pumped to $C l$ and $C 2$. The equivalent circuit and current path during this period is depicted in Figure 2(d).

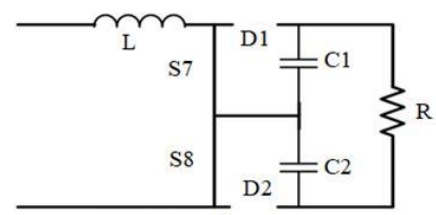

(a)

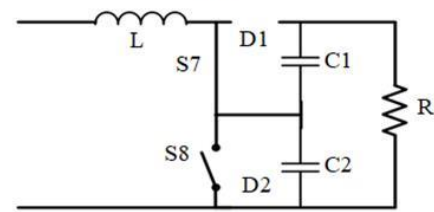

(c)

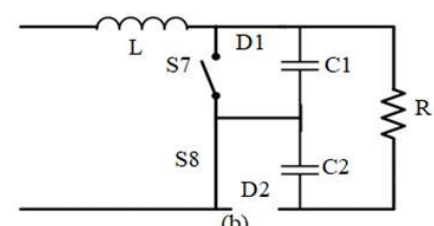

(b)

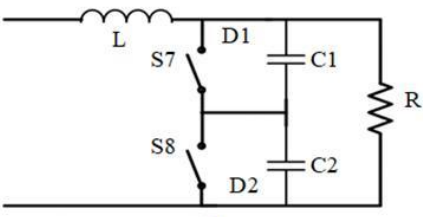

(d)

Figure 2. Equivalent circuit corresponding to mode operation states

\subsection{Static gain}

The static gain of the MLOBC can be obtained by applying the inductor voltage balanced law. The average inductor voltage value is zero at the steady-state. From the above equations, it is clear that mode 
1 and mode 4 corresponds to the conventional boost converter operation. However, when combined with mode2 and mode 3, MLOBC exhibits a superior output performance. The MLOBC has two distinct regions of operation, and that relies on the input voltage whether it is lower or higher than half of the output voltage. The first control region is considered and the duty cycle becomes greater than 0.5 when the input voltage is less than the output voltage of each capacitor (Vin $<\mathrm{Vo} / 2$ ). The two switches, S7 and S8, must not be "OFF" at the same time.

The sequence of the switching is "01-11-10-11-01" appears with duty cycle $(0.5<\delta 1<1,0.5<\delta 2<1$, where $\delta 1=\delta 2$ ). When the converter operates in Mode 1, Mode 2, Mode 1, Mode 3 and Mode 1 simultaneously, the balanced output voltage can be satisfied. The second control region is considered and the duty cycle $\left(D_{l}, D_{2}\right)$ becomes less than 0.5 when the input voltage is higher than each capacitor output voltage $($ Vin $>$ Vo/2). The sequence of the switching is "01-00-10-00-01" appears with duty cycle $(0<\delta 1<0.5,0<\delta 2$ $<0.5$, where $\delta 1=\delta 2$ ). The balanced output voltage can be achieved by operating the converter in Mode 2, Mode 4, Mode 2, Mode 3, and Mode 2 simultaneously.

$$
\begin{aligned}
& \text { Region } 1 \text { where }\left(\delta_{1}=\delta_{2}=\delta, 0.5<\delta<1\right) \\
& \frac{\mathrm{V}_{\mathrm{o}}}{\mathrm{V}_{\mathrm{in}}}=\frac{2}{(1-\delta)}
\end{aligned}
$$

Region 2 where $\left(\delta_{1}=\delta_{2}=\delta, 0<\delta<0.5\right)$ :

$$
\frac{\mathrm{V}_{\mathrm{o}}}{\mathrm{V}_{\mathrm{in}}}=\frac{1}{(1-\delta / 2)}
$$

\subsection{Voltage stress}

According to the analysis of operating principle in region 1 operation in Section 2, the voltage stress of $V_{D 1}$ and $V_{D 2}$ on the diodes $D 1$ and $D 2$ is given in (3) and as presented in Figure 2(a).

$$
\mathrm{V}_{\mathrm{D} 1}=\mathrm{V}_{\mathrm{D} 2}=\frac{1}{(1-\delta)} \mathrm{V}_{\mathrm{in}}
$$

The voltage stress of $V_{S 7}$ and $V_{S 8}$ on the swtiches $S_{7}$ and $S_{8}$ when the swtiches are off, are given in (4) as introduced in Figure 2(a).

$$
\mathrm{V}_{\mathrm{S} 7}=\mathrm{V}_{\mathrm{S} 8}=\frac{1}{(1-\delta)} \mathrm{V}_{\text {in }}
$$

The capacitors voltage stresses are given in (5).

$$
\mathrm{V}_{\mathrm{C} 1}=\mathrm{V}_{\mathrm{C} 2}=\frac{1}{(1-\delta)} \mathrm{V}_{\mathrm{in}}
$$

\subsection{Current stress}

The average output current is $I_{o}$. Ampere-second balance is applied to the capacitor $C 1, C 2$. The average current value of the capacitors in steady state is zero. With the assumption that the inductors are large enough, and there current change linearly in each operating mode, the average inductor current can be stated as:

$$
\mathrm{I}_{\mathrm{L}}=\frac{2}{(1-\delta)} \mathrm{I}_{\mathrm{o}}
$$

When switch $S 7$ is turned $\mathrm{ON}$, the currents of $S 7$ and the diode $D 2$ are:

$$
\mathrm{I}_{\mathrm{D} 2}=\mathrm{I}_{\mathrm{L}}=\frac{2}{(1-\delta)} \mathrm{I}_{\mathrm{o}}, \mathrm{I}_{\mathrm{S}}=\frac{2}{(1-\delta)} \mathrm{I}_{\mathrm{o}}
$$

When switch $S 8$ is turned $\mathrm{ON}$, the currents of $S 8$ and the diode $D l$ are:

$$
\mathrm{I}_{\mathrm{D} 1}=\mathrm{I}_{\mathrm{L}}=\frac{2}{(1-\delta)} \mathrm{I}_{\mathrm{o}}, \mathrm{I}_{\mathrm{S}}=\frac{2}{(1-\delta)} \mathrm{I}_{\mathrm{o}}
$$

Figure 3 illustrated four modes operation for different switching period. 

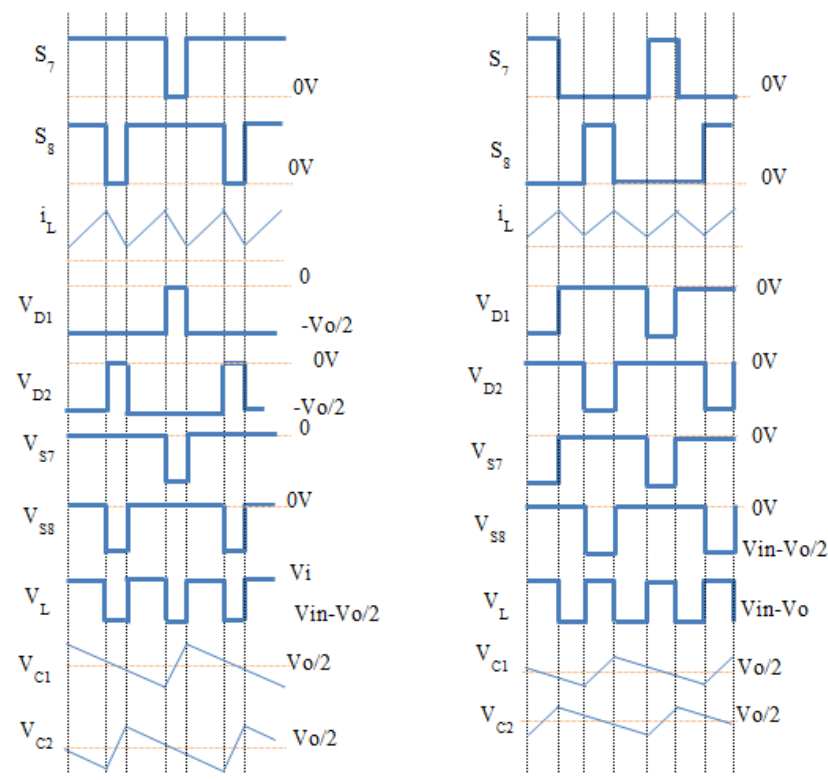

Figure 3. Effects of selecting different switching under dynamic condition

\section{RESULTS AND ANALYSIS}

The feasibility and effectiveness of the non-isolated multiple input and multi level output DC-DC converter for hybrid power system will be discussed. Simulations were carried out using the Matlab $\backslash$ Simulink software to examine the performance of the three input multi level output DC-DC converter. The initial element's values of the TIMLO DC-DC are the inductor $\mathrm{L}=1.13 \mathrm{mH}$, the capacitors $\mathrm{C} 1=\mathrm{C} 2=60 \mu \mathrm{F}$, the load resistor is $\mathrm{R}=550 \Omega$ and the switching frequency is $\mathrm{fs}=5 \mathrm{kHz}$. The ripples on the capacitors' voltage were limited to $1 \%$ of the mean voltage. It can be noticed that TIMLO converter has similar topology of the two conventional boost converters. Figure 4(a) shows the static gain of the TIMLO DC-DC converter and conventional boost converters. The simulation results obtained at $0 \mathrm{o}$ and180o phase shift between the control switches S7 and S8 shown in Figure 4(b), demonstrate the dynamical changing voltage stresses on the switches (S7 \& S8) and diodes (D1 \& D2) as well. The voltage stress on the switches (S7 \& S8) and diodes (D1 \& D2) reach half of the output voltage value. Figure 4(b) shows the voltage stress on the switches (S7 \& S8) and diodes (D1 \& D2).

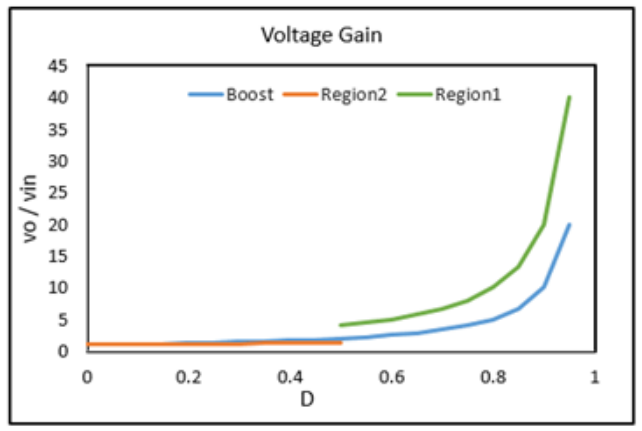

(a)

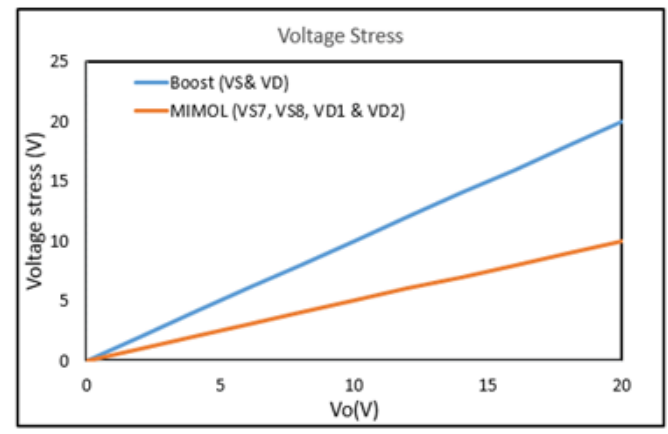

(b)

Figure 4. The steady-state behavior of the MIMOL converter and conventional boost converter: (a) Voltage-gain via duty cycles D, (b) Voltage stress on the switches (S7 \& S8) and diodes (D1 \& D2)

It is shown in Figure 5(a) that the voltage stress on the capacitor $\mathrm{C} 1$ and $\mathrm{C} 2$ is an intermediate voltage which is almost $262 \mathrm{~V}$. Also, it is observed that the ripple frequency of the capacitor voltages is doubled the switching frequency. The inductor current has been simulated as it is shown in Figure 5(b) as well. 


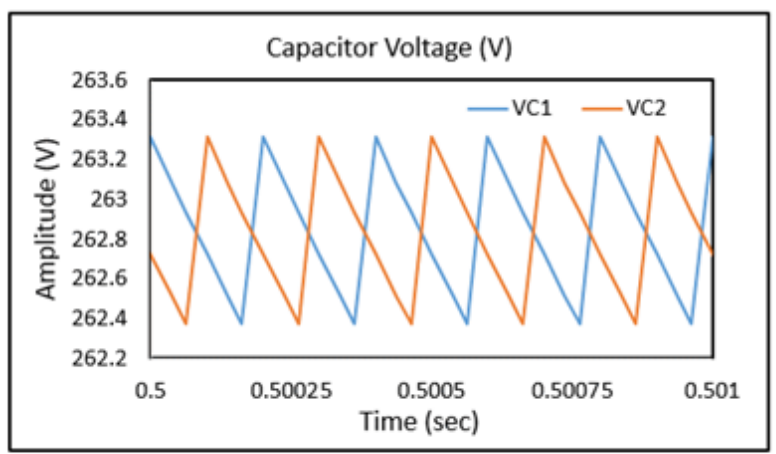

(a)

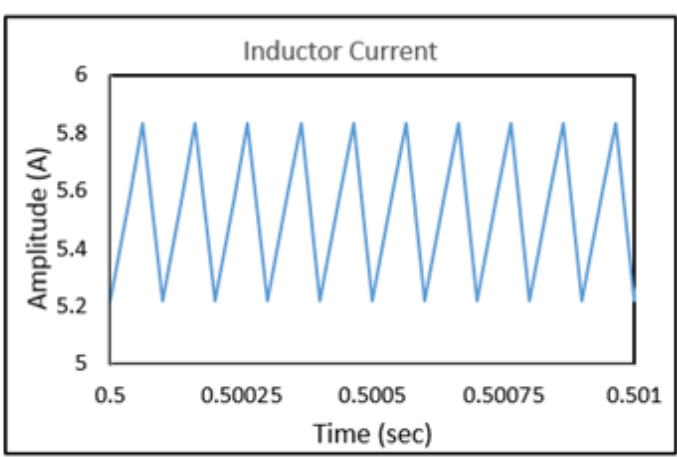

(b)

Figure 5. (a)Voltage stress on the capacitor $\mathrm{C} 1$ and $\mathrm{C} 2$, (b) Inductor current

For a wide range of operation for the input-voltage, the TIMLO converter with variable input voltages $(30 \mathrm{~V}, 40 \mathrm{~V}, 60 \mathrm{~V}, 70 \mathrm{~V}, \& 100 \mathrm{~V})$, output powers $(550 \mathrm{~W}, 1100 \mathrm{~W})$, and the constant output voltage $(525 \mathrm{~V})$ are simulated as illustrated in Figure 6 . It is interesting to notice the rise time, peak time and duty cycle are reduced as the input voltage increased. The overshoot and slew rate are increased with the increase in the input voltage as depicted in Table 2 . It can be easily observed that the input voltage is increased by 70 $\%$, the rise time reduced by $80 \%$, the peak time reduced by $73.33 \%$, the overshoot increased by $58.5 \%$, and the peak to peak voltage increased by $25.44 \%$. By analyzing the results depicted in Table 3 , the output voltage is proportionally increased as the input voltage increase with in a constant duty cycle. The simulation results favor the usage of multi input voltage, rather than a single input voltage.

In order to simplify the efficiency analysis of the TIMOL converter, the switching losses are neglected. The resistance of the inductor is addressed in the efficiency analysis. The range of efficiencies of the TIMOL converter was simulated as shown in Figure 7 with delimited minimum and maximum duty cycle and various input voltages. However, the curve of the efficiency of TIMOL converter, as a function of output voltage, gains its maximum value at an input voltage of $100 \mathrm{~V}$ and at a duty cycle of 0.5 . The efficiency value will decrease as the duty cycle increase too.

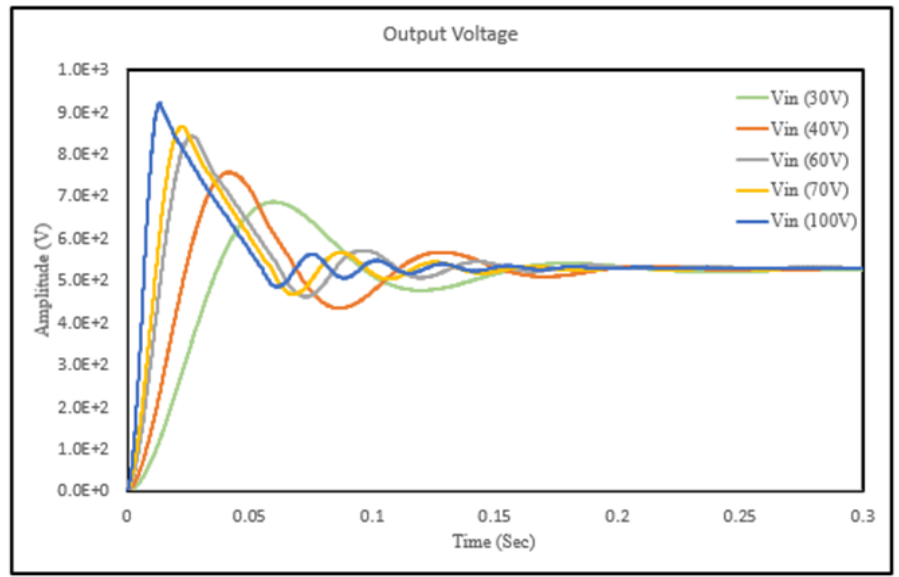

Figure 6. Output voltage of wide range of input-voltage

Table 2. Performance of the TIMLO converter

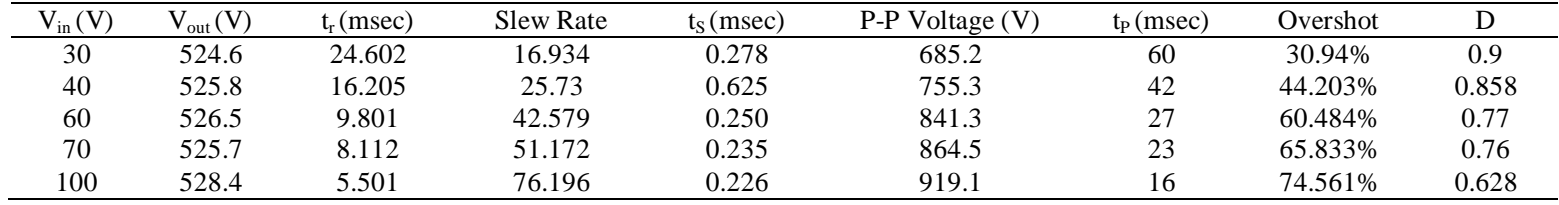


Table 3. Output voltage with variable input voltages and different duty cycle

\begin{tabular}{ccccc}
\hline \multirow{2}{*}{$\mathrm{V}_{\text {in }}(\mathrm{V})$} & \multicolumn{4}{c}{$\mathrm{V}_{\text {out }}(\mathrm{V})$} \\
& $\mathrm{D}=0.6$ & $\mathrm{D}=0.7$ & $\mathrm{D}=0.8$ & $\mathrm{D}=0.9$ \\
\hline 30 & 147.5 & 196.5 & 288.9 & 525.1 \\
40 & 197.2 & 262.5 & 385.6 & 700.5 \\
60 & 296.5 & 394.4 & 579.1 & 1051 \\
70 & 346.1 & 460.4 & 675.8 & 1227 \\
100 & 495 & 658.3 & 966.1 & 1753 \\
\hline
\end{tabular}

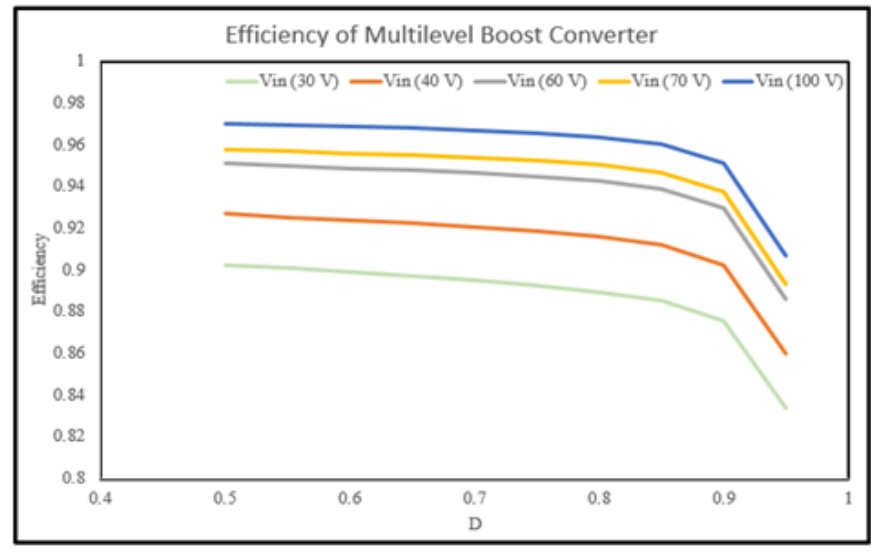

Figure 7. Efficiency with variable input voltages and different duty cycles

\section{CONCLUSION}

In this paper, a three input multi-level output DC-DC converter for a hybrid power system has been presented. To investigate the principle of operation of the generated structures, the multilevel output boost converter chosen has been simulated with various modes of operation using MatlablSimulink software. The high static gain between the input and output voltages are generated. This proposition is suitable for several applications such as fuel cell systems, wind energy systems, and photovoltaic systems. Moreover, one of the main advantages of the TIMOL converter is the reduction of voltage stress across the switches, S7 and S8. Another advantage is to reduce the reverse biased voltage or stress voltage on the diodes D1 and D2. A worth mentioning characteristic that can be noticed in the simulation results is that the efficiency improvement with the low rating switch. Also, high-efficiency of the converter topology can be achieved by various input sources related to renewable energy applications. Also, it can be easily moved from one power conversion system to another to satisfy high-voltage demands. The carried out work demonstrates the benefit of using multi input voltage over than single input voltage of DC-DC converter.

\section{REFERENCES}

[1] M. R. Banaei, et al., "Non-isolated multi-input-single-output DC/DC converter for photovoltaic power generation systems," IET Power Electronics, vol. 7, no. 11, pp. 2806-2816, Nov. 2014.

[2] T. Arunkumari, I. Jagadeesh and V. Indragandhi, "Design and implementation of modified multilevel sepic converter for PV applications," Indonesian Journal of Electrical Engineering and Computer Science (IJEECS), vol. 14, no. 3, pp. 1125-1133, Jun. 2019.

[3] F. Blaabjerg, Zhe Chen and S. B. Kjaer, "Power electronics as efficient interface in dispersed power generation systems," IEEE Transactions on Power Electronics, vol. 19, no. 5, pp. 1184-1194, Sept. 2004.

[4] D. B.Richardson. "Electric vehicles and the electric grid: A review of modeling approaches, Impacts, and renewable energy integration," Renewable and Sustainable Energy Reviews, vol. 19, pp 247-254, Mar. 2013.

[5] F. Sedaghati; et al., "A Configuration of Double Input Z-Source DC-DC Converter for Standalone PV/Battery System Application," Journal of Energy Management and Technology, vol. 2, no. 3,pp. 60-69, 2018.

[6] M. Mohammadi, et al., "Application of a New High Step-up Double-Input Converter in a Novel ModuleIntegrated-Inverter Photovoltaic System," IEEE Conferences (PEDSTC), Apr. 2015.

[7] A. A Chlaihaw, et al., "Novel screen printed and flexible low frequency magneto-electric energy harvester, " 2016 IEEE Sensors, Orlando, FL, pp. 1-3, 2016.

[8] E. Can and H. H. Sayan, "Different mathematical model for the chopper circuit, " Tehnički glasnik-Technical Journal, vol.10, no.1-2, pp. 13-15, 2016.

[9] T..Kousksou, et al., "Energy storage:Applicationsandchallenges," Solar EnergyMaterials \& SolarCells, vol. 120, pp. 59-80, Jan. 2014.

Non-isolated multiple input multilevel output DC-DC converter for hybrid power... (Ameen M. Al-Modaffer) 
[10] A. Nahavandi, et al., "A nonisolated multiinput multioutput DC-DC boost converter for electric vehicle applications," IEEE Transactions on Power Electronics, vol. 30, no. 4, pp. 1818-1835, Apr. 2015.

[11] A. Chlaihawi, "Genetic algorithm error criteria as applied to PID controller DC-DC buck converter parameters: an investigation, " IOP Conference Series: Materials Science and Engineering, vol. 671, pp. 1-10, 2020.

[12] E. Can, "PWM controlling of a new multi DC-DC converter circuit, " Tehnički glasnik-Technical Journal, vol.13, no.2, pp. 116-122, 2019.

[13] F. Kardan, R. Alizadeh and M. R. Banaei, "A New Three Input DC/DC Converter for Hybrid PV/FC/Battery Applications," IEEE Journal of Emerging and Selected Topics in Power Electronics, vol. 5, no. 4, pp. 1771-1778, Dec. 2017.

[14] Haixiong Ye, et al.,"High step-up interleaved dc/dc converter with high efficiency," Energy Sources, Part A: Recovery, Utilization, and Environmental Effects, Jan. 2020.

[15] A..Gani, et al.,"Design and development of PWM switching for 5-level multiphase interleaved DC/DC boost converter, " Indonesian Journal of Electrical Engineering and Computer Science (IJEECS), vol. 17, no. 1, pp. 131-140, Jan. 2020.

[16] M. D. Siddique, et al.,"A New Switched Capacitor 7L Inverter with Triple Voltage Gain and Low Voltage Stress," IEEE Transactions on Circuits and Systems, Aug. 2019.

[17] D. K. Srija, et al., "Performance analysis of non-isolated high step-up dc-dc converter topologies used in photovoltaic grid connected electric vehicle charging stations," 2019 Fifth International Conference on Electrical Energy Systems (ICEES), Chennai, India, pp. 1-6, 2019.

[18] T. Bascopé, et al., "Three-state switching cell (3SSC)-based non-isolated dc-dc boost-type converter with balanced output voltage and wide voltage conversion range," IET Power Electronics, vol. 11, no 7, pp. 1217-1223, 2018.

[19] X. Zhu, and B. Zhang," High step-up quasi-Z-source DC-DC converters with single switched capacitor branch," Journal of Modern Power Systems and Clean Energy, vol. 5, no 4, pp. 537-547, Jul. 2017.

[20] C. A. Villarreal, et al, "Modeling and control of an interleaved DC-DC multilevel boost converter," 2017 IEEE 18th Workshop on Control and Modeling for Power Electronics (COMPEL), Stanford, CA, pp. 1-6, 2017.

[21] K. Varesi, et a.l, "Performance and design analysis of an improved non-isolated multiple input buck DC-DC converter, " IET Power Electronics, vol. 10, no. 9, pp. 1034-1045, 2017.

[22] Z. Xia, B. L. Dobbins, J. S. Rentmeister and J. T. Stauth, "State Space Analysis of Flying Capacitor Multilevel DCDC Converters for Capacitor Voltage Estimation," 2019 IEEE Applied Power Electronics Conference and Exposition (APEC), Anaheim, CA, USA, pp. 50-57, 2019.

[23] Y. Zhang et al., "Wide Input-Voltage Range Boost Three-Level DC-DC Converter With Quasi-Z Source for Fuel Cell Vehicles," IEEE Transactions on Power Electronics, vol. 32, no. 9, pp. 6728-6738, Sep. 2017.

[24] X. Hu and C. Gong, "A High Gain Input-Parallel Output-Series DC/DC Converter With Dual Coupled Inductors," IEEE Transactions on Power Electronics, vol. 30, no. 3, pp. 1306-1317, Mar. 2015.

[25] A. Alzahrani, "Advanced topologies of high-voltage-gain DC-DC boost converters for renewable energy applications" Doctoral Dissertations, Department Electrical Engineering, Missouri University of Scince Techology, 2018.

[26] S. Rao, D. Kumar, C. Babu, " Grid Connected Distributed Generation System with High Voltage Gain Cascaded DC-DC Converter Fed Asymmetric Multilevel Inverter Topology, " International Journal of Electrical and Computer Engineering, vol. 8, no. 6, pp. 4047-4059, Dec. 2018.

[27] E. Can, " The Design and Experimentation of the New Cascaded Dc-Dc Boost Converter for Renewable Energy," International Journal of Electronics, 2019.

\section{BIOGRAPHIES OF AUTHORS}

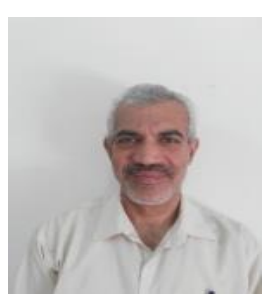

Ameen M. Al-Modaffer received the B.Sc. degree in Electrical Engineering and Education from the University of Technology, Baghdad, Iraq in 1984 and the M.Sc. degree in Instructional Technology from the University of Technology, Baghdad, Iraq in 1989. $\mathrm{He}$ is currently an assistance lecturer with the Department of Electrical Engineering, University of Kufa, Najaf Iraq. His research interests include design and fabrication of Labrotary equipment, simulation systems, power electronics, biomedical and magnetic sensing. Email: ameenm.hadi@uokufa.edu.iq

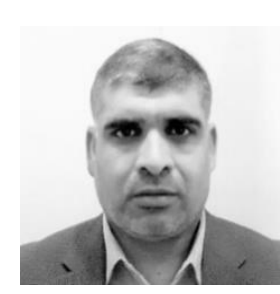

Dr. Amer A. Chlaihawi received the B.Sc. degree in Electrical and Electronic Engineering from University of Technology, Baghdad, Iraq in 1998; the M.Sc. degree in Electrical and Electronic Engineering from University of Technology, Baghdad, Iraq in 2001 and the Ph.D. degree from the Department of Electrical and Computer Engineering at Western Michigan University, Michigan USA in 2017. He is currently a lecturer with the Department of Electrical Engineering, University of Kufa, Najaf Iraq. His research interests include design, fabrication and characterization of printed sensor, printed electronics, power electronics, biomedical sensing, magnetic sensing, lab-on-a-chip, embedded system, smart sensing, and energy harvesting systems. Email: amera.chlaihawi@uokufa.edu.iq 


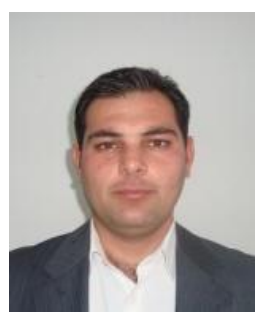

Husam A. Wahhab received the B.Sc. degree in Electronic Engineering from the University of Technology, Baghdad, Iraq in 2004 and the M.Sc. degree in Electronic Engineering from University of Technology, Baghdad, Iraq in 2013. He is currently an assistance lecturer with the Department of Electrical Engineering, University of Kufa, Najaf Iraq. His research interests include signal processing, power electronics, design and fabrication of electronic card.

Email: husama.aldujaili@uokufa.edu.iq 